University of New Orleans

ScholarWorks@UNO

1998

\title{
Novel electronic and magnetic properties of ultrathin chromium oxide films grown on $\mathrm{Pt}(111)$
}

\author{
P S. Robbert \\ University of New Orleans \\ H Geisler \\ C A. Ventrice Jr \\ $J$ van Ek \\ S Chaturvedi
}

See next page for additional authors

Follow this and additional works at: https://scholarworks.uno.edu/phys_facpubs

Part of the Physics Commons

\section{Recommended Citation}

J. Vac Sci. Technol. A 16, 990 (1998)

This Article is brought to you for free and open access by the Department of Physics at ScholarWorks@UNO. It has been accepted for inclusion in Physics Faculty Publications by an authorized administrator of ScholarWorks@UNO.

For more information, please contact scholarworks@uno.edu. 


\section{Authors}

P S. Robbert, H Geisler, C A. Ventrice Jr, J van Ek, S Chaturvedi, J A. Rodriguez, M Kuhn, and U Diebold 


\title{
Novel electronic and magnetic properties of ultrathin chromium oxide films grown on $\mathrm{Pt}(111)$
}

\author{
P. S. Robbert, H. Geisler, and C. A. Ventrice, Jr. ${ }^{\text {a) }}$ \\ Department of Plysics, University of New Orleans, New Orleans, Louisiana 70148 \\ J. van $\mathrm{Ek}^{\mathrm{b})}$ \\ Seagate Technology, Bloomington, Minnesota 55435 \\ S. Chaturvedi and J. A. Rodriguez ${ }^{\mathrm{c})}$ \\ Department of Chemistry, Brookhaven National Laboratory, Upton, New York 11973 \\ M. Kuhn ${ }^{\text {d) }}$ and U. Diebold ${ }^{\circledR)}$ \\ Department of Physics, Tulane University, New Orleans, Louisiana 70118
}

(Received 28 October 1997; accepted 19 January 1998)

\begin{abstract}
The growth of epitaxial metal-oxide films on lattice-mismatched metal substrates often results in the formation of unique overlayer structures. In particular, epitaxial chromium oxide films grown on $\mathrm{Pt}(111)$ exhibit a $p(2 \times 2)$ symmetry through the first two monolayers of growth which is followed by a $(\sqrt{3} \times \sqrt{3}) \mathrm{R} 30^{\circ}$ phase that is attributed to the growth of a $\mathrm{Cr}_{2} \mathrm{O}_{3}(0001)$ overlayer. Ultraviolet photoelectron spectroscopy measurements have been performed on the $\mathrm{CrO}_{x} / \mathrm{Pt}(111)$ system. The electronic structures of $\mathrm{CrO}_{2}, \mathrm{Cr}_{2} \mathrm{O}_{3}$, and $\mathrm{Cr}_{3} \mathrm{O}_{4}$ were calculated using the linear muffin-tin orbital method in the atomic sphere approximation. Comparison of the photoemission valence band spectra with the calculated density of states indicates that the $\mathrm{CrO}_{x}$ initially grows in a cubic spinel $\mathrm{Cr}_{3} \mathrm{O}_{4}$ structure. Beyond $\sim 0.2$ monolayers, the metallic behavior of the $\mathrm{CrO}_{x}$ overlayer begins a transformation to an insulating state. The measured valence emission for the $p(2 \times 2)$ phase beyond $\sim 0.2$ monolayers is more consistent with either a $\gamma-\mathrm{Cr}_{2} \mathrm{O}_{3}(111)$ overlayer or possibly a reconstructed $\mathrm{Cr}_{2} \mathrm{O}_{3}(0001)$ overlayer. (C) 1998 American Vacuum Society.

[S0734-2101(98)03503-9]
\end{abstract}

\section{INTRODUCTION}

In recent years, the study of the growth of epitaxial metal-oxide/metal interfaces has become a topic of great interest within the surface science community. Besides the advantage of eliminating sample charging problems while performing electron or ion spectroscopies on insulating surfaces, this technique of growing metal oxides also opens up a whole new class of materials that can be studied. For instance, the interaction between the substrate and the metaloxide overlayer can often result in new structures that are not thermodynamically stable in their bulk forms. One example of this is iron oxide growth on $\mathrm{Pt}(111)$ where a well-ordered $\mathrm{FeO}(111)$ overlayer, which is not a stable bulk phase of iron oxide at room temperature, is observed during the first monolayer (ML) of growth. ${ }^{1,2}$ For $\mathrm{NaCl}$ structured metal oxides, stable, polar, surface terminations are not observed for bulk single crystals without the introduction of surface impurities. However, a $p(2 \times 2)$ reconstructed polar $\mathrm{NiO}(111)$ surface can be formed during the first few monolayers of growth on the $\mathrm{Au}(111)$ substrate. ${ }^{3,4}$ In addition, for several

\footnotetext{
${ }^{a)}$ Electronic mail: CAVPH@uno.edu

b)Electronic mail: johannes_van_ek@notes.seagate.com

${ }^{c)}$ Electronic mail: rodrigez@bnl.gov

(j) Present address: Digital Equipment Corporation, 77 Reed Rd., Hudson, MA 01749.

e)Electronic mail: diebold@mailhost.tcs.tulane.edu
}

metal oxides high-quality bulk single crystals are not readily available, yet well-ordered ultrathin films can often be grown on various single-crystal metal substrates. ${ }^{5}$

Chromium oxide ultrathin films are of interest due to the wide variety of their technological applications. The most stable phase of chromium oxide is the corundum structured $\mathrm{Cr}_{2} \mathrm{O}_{3}$. This form of the oxide is an important industrial catalyst which is often used in polymerization reactions. In addition, the passivating of stainless steel is accomplished by the formation of a $\mathrm{Cr}_{2} \mathrm{O}_{3} / \mathrm{NiO}$ surface complex. Another stable form of chromium oxide is $\mathrm{CrO}_{2}$. It is a conducting ferromagnet and is used in magnetic recording media because of its resistance to corrosion and its high coercivity. Above $280^{\circ} \mathrm{C}, \mathrm{CrO}_{2}$ decomposes into $\mathrm{Cr}_{2} \mathrm{O}_{3}{ }^{6}$ The stable form of chromium oxide above $\sim 1600^{\circ} \mathrm{C}$ is a tetragonally distorted $\mathrm{Cr}_{3} \mathrm{O}_{4}$ spinel phase. ${ }^{7}$ The formation of a cubic spinel $\gamma-\mathrm{Cr}_{2} \mathrm{O}_{3}$ has also been reported under certain thin-film growth conditions. ${ }^{8}$ Well-ordered single crystals of any of the phases of chromium oxide are not readily available.

The growth of chromium oxide on the $\mathrm{Pt}(111)$ surface has been studied previously by Zhang et al. using low energy electron diffraction (LEED), scanning tunneling microscopy (STM), x-ray photoelectron spectroscopy (XPS), and ion scattering spectroscopy (ISS). ${ }^{9}$ The LEED results indicate the formation of a film with a $p(2 \times 2)$ pattern with respect to the $\mathrm{Pt}(111)$ substrate during the initial $2 \mathrm{ML}$ of growth which is followed by the formation of $(\sqrt{3} \times \sqrt{3}) \mathrm{R} 30^{\circ}$ pattern at higher coverages. The growth morphology observed with 
STM shows that the $\mathrm{CrO}_{x}$ initially nucleates at step edges and then propagates out in a step flow growth mode with a 2 ML film height. Monitoring of the $\mathrm{Cr} 2 p$ core emission with XPS has revealed a broadening of the emission in the $p$ (2 $\times 2)$ regime with respect to the $(\sqrt{3} \times \sqrt{3}) \mathrm{R} 30^{\circ}$ regime. In addition, no intermixing of $\mathrm{Pt}$ in the $\mathrm{CrO}_{x}$ film is observed with ISS. The $(\sqrt{3} \times \sqrt{3}) \mathrm{R} 30^{\circ}$ epitaxial phase has been attributed to a $\mathrm{Cr}_{2} \mathrm{O}_{3}(0001)$ overlayer since this would produce a $(\sqrt{3} \times \sqrt{3}) \mathrm{R} 30^{\circ}$ LEED pattern with respect to the Pt(111) substrate. The results for the $p(2 \times 2)$ phase give evidence for the formation of a $\mathrm{Cr}_{3} \mathrm{O}_{4}$ cubic spinel phase. Along the [111] direction, the spinel structure consists of close-packed oxygen layers in an $A B C-A B C$ stacking pattern. Between each oxygen layer is a chromium layer with either only octahedrally coordinated or both tetrahedrally and octahedrally coordinated $\mathrm{Cr}$ ions. Therefore, broadening of the $\mathrm{Cr} 2 p$ emission is expected since there are two distinct $\mathrm{Cr}$ coordinations, and a $2 \mathrm{ML}$ growth mode is expected since the repeat unit consists of two close-packed oxygen layers with their respective $\mathrm{Cr}$ intralayers.

In this article, the results of synchrotron-based ultraviolet photoelectron spectroscopy (UPS) measurements of the valence structure of chromium oxide films grown on a $\mathrm{Pt}(111)$ substrate are presented. Calculations of the bulk electronic structures of $\mathrm{CrO}_{2}, \mathrm{Cr}_{2} \mathrm{O}_{3}$, and $\mathrm{Cr}_{3} \mathrm{O}_{4}$ using the linear muffin-tin orbital method in the atomic sphere approximation (LMTO-ASA) have also been performed. These calculations predict metallic behavior for both $\mathrm{CrO}_{2}$ and $\mathrm{Cr}_{3} \mathrm{O}_{4}$. In addition, $\mathrm{CrO}_{2}$ is predicted to have the unique property of being a perfect half-metallic ferromagnet, and the $\mathrm{Cr}_{3} \mathrm{O}_{4}$ calculations show an almost perfect half-metallic ferrimagnetic behavior. For $\mathrm{Cr}_{2} \mathrm{O}_{3}$, an insulating antiferromagnetic behavior is predicted. The results of the electronic structure calculations are compared with the UPS measurements. Within the $(\sqrt{3} \times \sqrt{3}) \mathrm{R} 30^{\circ}$ chromium oxide growth regime, there is good agreement between the valence structure measured with UPS and the calculated electronic structure of $\mathrm{Cr}_{2} \mathrm{O}_{3}$. At coverages less than $\sim 0.2 \mathrm{ML}$, a metallic behavior for the overlayer is observed, and the electronic structure calculated for $\mathrm{Cr}_{3} \mathrm{O}_{4}$ closely mimics the UPS measurements. The measured valence structure of the $p(2 \times 2)$ overlayer beyond $\sim 0.2 \mathrm{ML}$ shows a transition to an insulating behavior similar to the $(\sqrt{3} \times \sqrt{3}) \mathrm{R} 30^{\circ}$ regime. This valence structure is indicative of either a $\gamma-\mathrm{Cr}_{2} \mathrm{O}_{3}(111)$ or a reconstructed $\mathrm{Cr}_{2} \mathrm{O}_{3}(0001)$ overlayer.

The reactivity of the $\mathrm{CrO}_{x}$ films towards $\mathrm{H}_{2} \mathrm{~S}$ adsorption has also been examined with UPS. Since the primary emphasis of this article is the electronic and magnetic structure of the $\mathrm{CrO}_{x}$ films, the chemical properties of these films have been published in a separate article. ${ }^{10}$

\section{EXPERIMENTAL PROCEDURE}

The UPS measurements were performed at the National Synchrotron Light Source (NSLS) at Brookhaven National Laboratory. The primary measurements for this study were carried out at beamline U4A which is equipped with a $6 \mathrm{~m}$ toroidal grating monochrometer (TGM). The ultrahigh vacuum (UHV) end station incorporates a hemispherical analyzer for detection of the photoelectrons, a LEED apparatus, and a sputter gun for cleaning the sample. The base pressure of the chamber was $4 \times 10^{-10}$ Torr. Cleaning of the $\mathrm{Pt}(111)$ crystal was achieved by sputtering with $\mathrm{Ne}$ ions at $1000 \mathrm{eV}$ for $\sim 45 \mathrm{~min}$, followed by annealing the sample to $1000^{\circ} \mathrm{C}$ for $5 \mathrm{~min}$. The sample was heated by electron bombardment from a Ta filament. The $x-y$ sample manipulator which was used for the measurements at U4A could not bring the sample within the focal point of the fixed position LEED spectrometer which made determining overlayer structures difficult. Therefore, to confirm the transition from the $p(2$ $\times 2)$ to the $(\sqrt{3} \times \sqrt{3}) \mathrm{R} 30^{\circ}$ regime, measurements were also made at U7B which had a movable LEED spectrometer. The comparison of the coverages in each system was achieved by measuring the relative heights of the $\mathrm{Cr} 2 p$ and $\mathrm{Pt} 4 f$ core emissions. The U7B beamline is equipped with a plane grating monochrometer (PGM). The end station incorporates similar instrumentation as U4A, except the base pressure was only $8 \times 10^{-10}$ Torr, and the heating of the sample was achieved by resistive heating of two $0.25 \mathrm{~mm}$ diameter tungsten wires that were spot welded to the back of Pt(111) crystal. The maximum sample temperature achieved using resistive heating was $\sim 700^{\circ} \mathrm{C}$. Since the system resolution at U4A is much higher than that at U7B $(\sim 100$ and $\sim 500 \mathrm{meV}$, respectively) over the energy range of interest in this study, only UPS spectra from the U4A run are presented in this article.

Chromium was deposited in both systems using a $\mathrm{Cr}$ pellet which was enclosed in a resistively heated tungsten wire basket. The evaporator was equipped with a Ta thermal shield and a shutter to control deposition times. The $\mathrm{CrO}_{x}$ films were grown by backfilling the chamber with $\mathrm{O}_{2}$ to $p$ $=2 \times 10^{-6}$ Torr and evaporating $\mathrm{Cr}$ at a rate of $\sim 0.2 \mathrm{ML} / \mathrm{min}$ while maintaining the $\mathrm{Pt}(1,11)$ crystal at $\sim 300^{\circ} \mathrm{C}$. As mentioned previously, Zhang et al. ${ }^{9}$ have determined that the conversion of the LEED from a $p(2 \times 2)$ to a $(\sqrt{ } 3 \times \sqrt{ } 3) \mathrm{R} 30^{\circ}$ pattern occurs at $2 \mathrm{ML}$ of $\mathrm{CrO}_{x}$ coverage. This was determined from coverage measurements with a quartz crystal microbalance (QCM) and ISS results. Since neither chamber at the NSLS had a QCM or ISS capabilities, our $\mathrm{CrO}_{x}$ coverages are based on the conversion of the LEED image from the $p(2 \times 2)$ to a $(\sqrt{3} \times \sqrt{3}) \mathrm{R} 30^{\circ}$ pattern and are estimated to be accurate within $\pm 50 \%$.

\section{METHODOLOGY OF BULK BAND STRUCTURE CALCULATIONS}

The electronic structure calculations were performed using the LMTO-ASA method. ${ }^{11}$ Exchange and correlation effects are treated within the local spin-density approximation (LSDA) of density functional theory (DFT). ${ }^{12}$ Self-consistent solutions to the Kohn-Sham equations are obtained for all electrons in the system using the exchange-correlation potential as parameterized by von Barth and Hedin. ${ }^{13}$ The coreelectron states are solutions of the single-particle Dirac equation. Scalar relativistic terms are included in the Hamiltonian for the valence and conduction bands. The LMTO basis set 


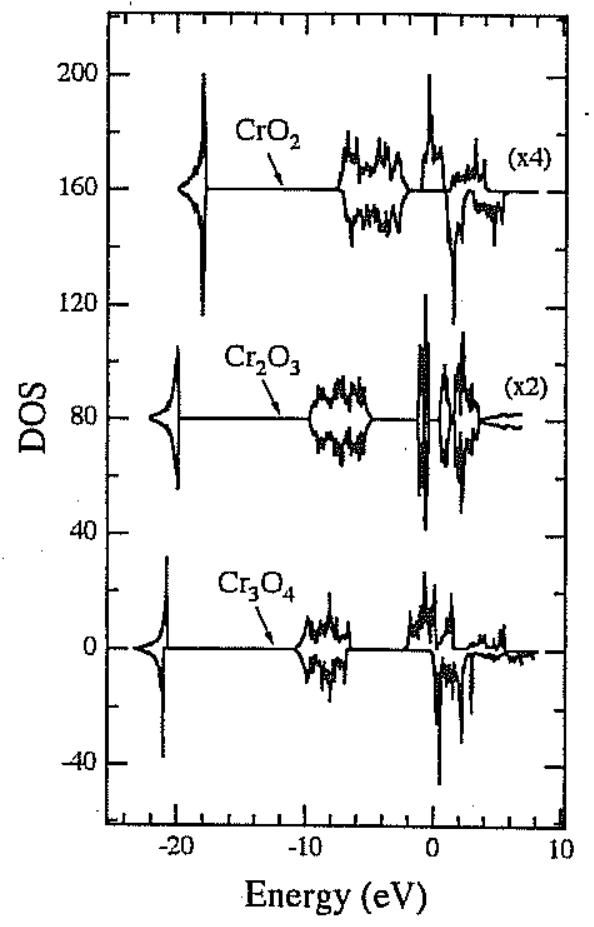

Fig. 1. Calculated spin-resolved density of states for $\mathrm{CrO}_{2}, \mathrm{Cr}_{2} \mathrm{O}_{3}$, and $\mathrm{Cr}_{3} \mathrm{O}_{4}$. The majority/minority spin channel is plotted as a positive/negative density of states value.

included $4 s, 4 p$, and $3 d$-type functions for $\mathrm{Cr}$, and $2 s$ and $2 p$-type functions for $\mathrm{O}$. Pivotal energies on each site were chosen at the center of gravity of the occupied partial density of states. For $\mathrm{CrO}_{2}$ empty spheres were introduced in order to improve the description of the interstitial region. Positions of the empty spheres and the sphere radii for all sites were taken from Ref. 14. Atomic sphere radii were taken to be equal for all atoms in $\mathrm{Cr}_{2} \mathrm{O}_{3}$ and $\mathrm{Cr}_{3} \mathrm{O}_{4}$, and no empty spheres were employed. A sufficient number of $k$ points was used to sample the irreducible wedges of the Brillouin zones of the three crystals.

The calculations for the rutile-structured $\mathrm{CrO}_{2}$ and the corundum-structured $\mathrm{Cr}_{2} \mathrm{O}_{3}$ were performed using the experimentally determined lattice parameters. ${ }^{8}$ We know of no previously published experimental data for a bulk-phase, cubic, spinel structured $\mathrm{Cr}_{3} \mathrm{O}_{4}$. In comparison to the related iron oxide phases, it is noted that there is only a $2 \%$ difference in the $\mathrm{O}-\mathrm{O}$ spacing of $\alpha-\mathrm{Fe}_{2} \mathrm{O}_{3}$ and $\mathrm{Fe}_{3} \mathrm{O}_{4}$. Therefore, a lattice parameter of $a_{0}=8.09 \AA$, which corresponds to the same $\mathrm{O}-\mathrm{O}$ nearest neighbor spacing as $\mathrm{Cr}_{2} \mathrm{O}_{3}\left(d_{\mathrm{O}-\mathrm{O}}\right.$ $=2.86 \AA$ ) , was used to calculate electronic structure of the cubic, spinel structured $\mathrm{Cr}_{3} \mathrm{O}_{4}$. This assumption results in a mismatch of $3 \%$ between the surface nets of $\mathrm{Cr}_{3} \mathrm{O}_{4}(111)$ and a $p(2 \times 2) \mathrm{Pt}(111)$ which is consistent with the previous LEED results. ${ }^{9}$

\section{RESULTS}

\section{A. Spin-resolved electronic structure calculations}

The calculated density of states (DOS) for $\mathrm{CrO}_{2}, \mathrm{Cr}_{2} \mathrm{O}_{3}$, and $\mathrm{Cr}_{3} \mathrm{O}_{4}$ is shown in Fig. 1. For $\mathrm{CrO}_{2}$, the majority spin states cross the Fermi level while the minority spin channel is insulating. Hence, $\mathrm{CrO}_{2}$ is a half-metallic ferromagnet which is in agreement with the theoretical results of Refs. 14 and 15. As a result of this behavior, the perfect bulk value of the magnetic moment per formula unit is integer $2 \mu_{B}$, where $\mu_{B}$ is the Bohr magneton. Spin-orbit coupling has very little effect on the half-metallic ferromagnetic character of the DOS, as judged from the calculated moment per formula unit of $1.9992 \mu_{B}$. The majority and minority $\mathrm{Cr} 3 d$ bands are exchange split by about $2 \mathrm{eV}$.

The calculated DOS of $\mathrm{Cr}_{2} \mathrm{O}_{3}$ is shown in Fig. 1. This oxide is an antiferromagnetic insulator. With values of plus and minus $2.8 \mu_{B}$, the moments on the $\mathrm{Cr}$ atoms in $\mathrm{Cr}_{2} \mathrm{O}_{3}$ are larger than those in $\mathrm{CrO}_{2}$. The $\mathrm{Cr} 3 d$ valence band is only $\sim 1 \mathrm{eV}$ wide and is separated from the conduction band by an energy gap of $0.9 \mathrm{eV}$. Since the experimentally determined band gap of $\mathrm{Cr}_{2} \mathrm{O}_{3}$ is $3.2 \mathrm{eV},{ }^{16,17}$ these calculations significantly underestimate the magnitude of the band gap which is typical for DFT calculations. The energy separation between the $\mathrm{O} 2 s$ and $\mathrm{O} 2 p$ bands is the same as in $\mathrm{CrO}_{2}$, but both bands are shifted by $\sim 2 \mathrm{eV}$ to higher binding energy. In addition, the $\mathrm{O} 2 p$ band of $\mathrm{Cr}_{2} \mathrm{O}_{3}$ is $\sim 5 \mathrm{eV}$ wide which is $-0.5 \mathrm{eV}$ narrower than that for $\mathrm{CrO}_{2}$.

The calculated DOS for a hypothetical $\mathrm{Cr}_{3} \mathrm{O}_{4}$ having the spinel structure of its iron oxide analog $\mathrm{Fe}_{3} \mathrm{O}_{4}$ is shown in Fig. 1. The width of the $\mathrm{O} 2 p$ band is $\sim 4 \mathrm{eV}$ which is narrower than that for either $\mathrm{CrO}_{2}$ or $\mathrm{Cr}_{2} \mathrm{O}_{3}$. In addition, both the $\mathrm{O} 2 p$ and $\mathrm{O} 2 s$ bands have shifted $\sim 1.5 \mathrm{eV}$ higher in binding energy than the $\mathrm{Cr}_{2} \mathrm{O}_{3}$ oxygen bands. The width of the $3 d$ band is close to that of the $\mathrm{CrO}_{2}$ band, and the system is very close to being a half-metallic ferrimagnet. Moments on the two inequivalent $\mathrm{Cr}$ atoms are approximately $-1.7 \mu_{B}$ and $3.2 \mu_{B}$, respectively. The ferrimagnetic ordering in $\mathrm{Cr}_{3} \mathrm{O}_{4}$ is similar to that found in $\mathrm{Fe}_{3} \mathrm{O}_{4}$ from LSDA calculations.

Since the photoemission measurements reported in this article are not spin resolved, a compilation of the calculated total density of occupied states (sum of minority and majority DOS multiplied by the Fermi function) is shown in Fig. 2 for comparison with the photoemission measurements. There are several differences which are observed in the calculated electronic structures of $\mathrm{CrO}_{2}, \mathrm{Cr}_{2} \mathrm{O}_{3}$, and $\mathrm{Cr}_{3} \mathrm{O}_{4}$. As described in the previous section, both $\mathrm{CrO}_{2}$ and $\mathrm{Cr}_{3} \mathrm{O}_{4}$ are predicted to be metallic, and there is a successive shift to higher binding energies for the $\mathrm{O} 2 p$ band from $\mathrm{CrO}_{2}$ to $\mathrm{Cr}_{3} \mathrm{O}_{4}$. In addition, the relative height of the $\mathrm{Cr} 3 d$ DOS to that of $\mathrm{O}_{2} p$ is approximately unity for $\mathrm{CrO}_{2}$ and $\mathrm{Cr}_{3} \mathrm{O}_{4}$; whereas, the height of the $\mathrm{Cr} 3 p$ DOS is approximately twice that of $\mathrm{O} 2 p$ for $\mathrm{Cr}_{2} \mathrm{O}_{3}$.

\section{B. Ultraviolet photoelectron spectroscopy measurements}

A series of UPS spectra for $\mathrm{CrO}_{x}$ coverages up to $\sim 4 \mathrm{ML}$ is shown in Fig. 3. At a coverage of $4 \mathrm{ML}$, no emission features from the Pt(111) substrate are observed; whereas, a superposition of $\mathrm{Pt}(111)$ and $\mathrm{CrO}_{x}$ features are observed for 


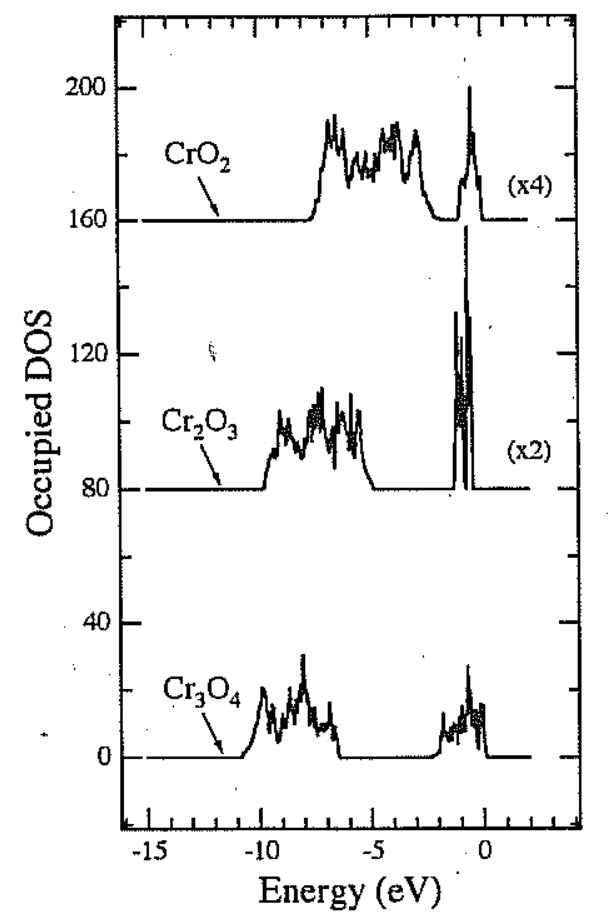

FIG. 2. Calculated total density of occupied states for the valence region of $\mathrm{CrO}_{2}, \mathrm{Cr}_{2} \mathrm{O}_{3}$, and $\mathrm{Cr}_{3} \mathrm{O}_{4}$.

the three lower coverages. Spectra from both the clean $\mathrm{Pt}(111)$ surface and the surface dosed with $50 \mathrm{~L}$ of $\mathrm{O}_{2}$ are also shown in this series. Slight changes in the valence emission are observed after oxygen dosing which indicates that

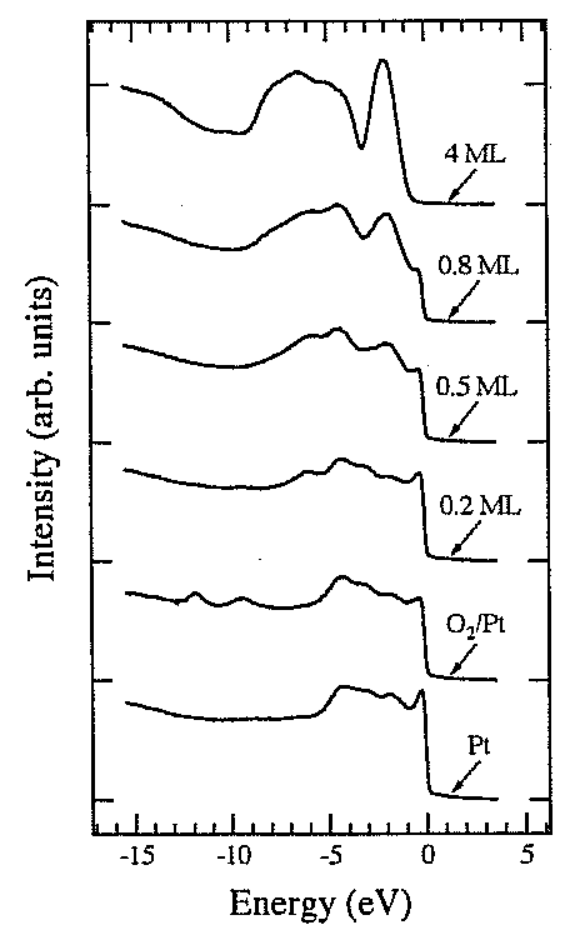

Fig. 3. Measured UPS spectra for $\mathrm{CrO}_{x} / \mathrm{Pt}(111)$ coverages up to $-4 \mathrm{ML}$. The $\mathrm{O}_{2} / \mathrm{Pt}(111)$ spectrum corresponds to the dosing of $50 \mathrm{~L}$ of oxygen on the clean $P_{t}$ surface without dosing $\mathrm{Cr}$. All spectra were taken with $p$-polarized light at an angle of incidence of $\alpha=45^{\circ}$, a photon energy of 50 $\mathrm{eV}$, and normal emission.

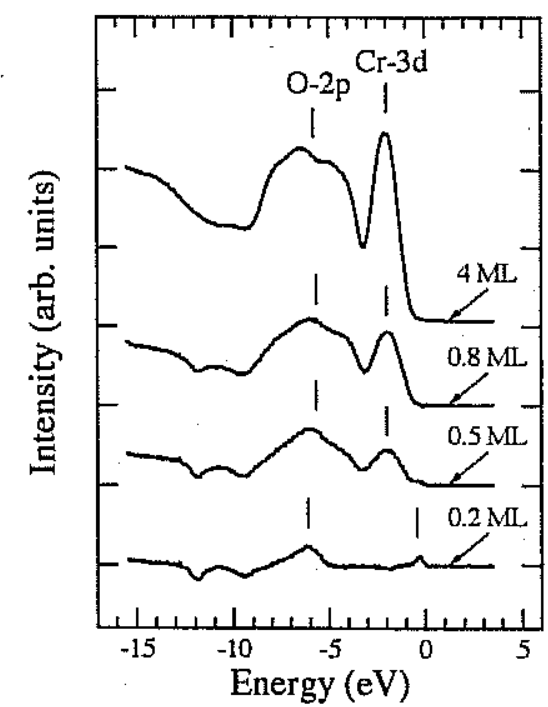

FIG. 4. A series of UPS difference spectra generated by subtracting the normalized $\mathrm{O}_{2} / \mathrm{Pt}(111)$ spectrum from each $\mathrm{CrO}_{x} / \mathrm{Pt}(111)$ spectrum. The three lowest $\mathrm{CrO}_{x}$ coverages correspond to the observance of the $p(2 \times 2)$ phase and the $4 \mathrm{ML}$ coverage to the $(\sqrt{3} \times \sqrt{3}) \mathrm{R} 30^{\circ}$ phase.

trace amounts of oxygen are adsorbed on the Pt surface. In addition, two small peaks at $\sim 9 \mathrm{eV}$ and $\sim 12 \mathrm{eV}$ are observed which corresponds to the adsorption of $\mathrm{CO}$ during the oxygen dosing.

To better differentiate the $\mathrm{CrO}_{x}$ emission features from the Pt features, a series of difference spectra were generated. by subtracting the normalized $\mathrm{O}_{2} / \mathrm{Pt}(111)$ spectrum from each $\mathrm{CrO}_{x} / \mathrm{Pt}(111)$ spectrum and are shown in Fig. 4. The oxygen dosed Pt spectrum was chosen for the subtraction instead of the clean $\mathrm{Pt}$ to account for trace amounts of oxygen which adsorb on the Pt regions of the surface during $\mathrm{CrO}_{x}$ growth. The scale factors for the normalization were determined by calculating the ratio of the height of the emission near the Fermi edge of each $\mathrm{CrO}_{x} / \mathrm{Pt}(111)$ spectrum to the height of the $\mathrm{O}_{2} / \mathrm{Pt}(111)$ Fermi edge. To check the accuracy of this procedure, difference spectra were also generated using the relative attenuation of the Pt. $4 f$ emissions to determine the scale factors, and these spectra showed similar results to those generated using the ratios of the Fermi edges. The three lowest $\mathrm{CrO}_{x}$ coverages in Fig. 4 are within the region where a $p(2 \times 2)$ overlayer is observed, and the $4 \mathrm{ML}$ spectrum is within the $(\sqrt{3} \times \sqrt{ } 3) \mathrm{R} 30^{\circ}$ region and corresponds to a $\mathrm{Cr}_{2} \mathrm{O}_{3}(0001)$ overlayer. From comparison of the $4 \mathrm{ML}$ spectrum with the DOS for $\mathrm{Cr}_{2} \mathrm{O}_{3}$ in Fig. 2, it can be seen that the $\mathrm{Cr} 3 d$ band is shifted $\sim 1 \mathrm{eV}$ higher in binding energy than is predicted by the DOS calculations, and the $\mathrm{O} 2 p$ band is shifted $\sim 1.5 \mathrm{eV}$ to lower binding energy. These shifts are in agreement with previously published UPS results for the $\mathrm{Cr}_{2} \mathrm{O}_{3}(0001) / \mathrm{Cr}(110)$ system. ${ }^{18}$ There is no apparent shift in the positions of the $\mathrm{Cr} 3 d$ and $\mathrm{O} 2 p$ bands of the 0.5 and $0.8 \mathrm{ML}$ coverages with respect to those of the $4 \mathrm{ML}$ overlayer. However, there is a change in the ratio of the heights of the $\mathrm{Cr} 3 d$ intensity to that of the $\mathrm{O} 2 p$ intensity: 0.7 for the $0.5 \mathrm{ML}$ coverage, 1.0 for the $0.8 \mathrm{ML}$ coverage, and 1.4 for the $4 \mathrm{ML}$ coverage. The most dramatic 
changes in the UPS spectra occur for the $0.2 \mathrm{ML}$ coverage. At this coverage, emission near the Fermi level is observed, the $\mathrm{O} 2 p$ emission is only $\sim 4 \mathrm{eV}$ wide, and the onset of $\mathrm{O} 2 p$ emission is shifted $\sim 2 \mathrm{eV}$ higher in binding energy than for the spectra at higher coverages. Another feature which is observed for the three lowest coverages is two "negative" peaks at $\sim 9 \mathrm{eV}$ and $\sim 12 \mathrm{eV}$. These peaks arise from $\mathrm{CO}$ which has adsorbed on the oxygen dosed $\mathrm{Pt}(111)$ surface and is not present on the surface after $\mathrm{CrO}_{x}$ growth at $300^{\circ} \mathrm{C}$.

\section{DISCUSSION}

The UPS spectrum in Fig. 4 which most closely resembles the DOS of the $\mathrm{Cr}_{3} \mathrm{O}_{4}$ is from the $0.2 \mathrm{MLCrO}$ coverage. An $\sim 0.5 \mathrm{eV}$ wide emission feature is observed just below the Fermi level which indicates that the overlayer is metallic. A remnant of this peak is also observed for the $0.5 \mathrm{ML}$ coverage but is missing at higher coverages. In addition, the onset of emission from the $\mathrm{O} 2 p$ band is shifted $\sim 2 \mathrm{eV}$ to higher binding energy in comparison with the other coverages which agrees with the difference in the calculated onsets for $\mathrm{Cr}_{2} \mathrm{O}_{3}$ and $\mathrm{Cr}_{3} \mathrm{O}_{4}$. Although the onset of emission from the $\mathrm{O} 2 p$ band is $\sim 1.5 \mathrm{eV}$ lower in binding energy than what is predicted by the calculated DOS, this same behavior is observed for the $4 \mathrm{ML}$ spectrum when compared to the calculated DOS for $\mathrm{Cr}_{2} \mathrm{O}_{3}$ which indicates that this is a systematic error of the calculation technique.

The nature of the $p(2 \times 2)$ phase which is observed beyond $\sim 0.2 \mathrm{ML}$ of $\mathrm{CrO}_{x}$ coverage is somewhat uncertain. One possible explanation is that the calculated ground state electronic structure of $\mathrm{Cr}_{3} \mathrm{O}_{4}$ incorrectly represents the electronic structure observed. via photoemission. A previous spin-resolved photoemission study of polycrystalline $\mathrm{CrO}_{2}$ films ${ }^{19}$ indicates that this is the case for the calculated DOS. of $\mathrm{CrO}_{2}$. Almost $100 \%$ spin polarization was observed for the $\mathrm{Cr} 3 d$ emission from their polycrystalline $\mathrm{CrO}_{2}$ films which agrees with the prediction that the minority spin channel has no DOS below the Fermi level. However, the onset of the $\mathrm{Cr} 3 d$ emission was observed at $\sim 1.5 \mathrm{eV}$ below the Fermi level which contradicts both our and previous DOS calculations ${ }^{14,15}$ and experimental resistivity measurements ${ }^{6,20}$ which indicate that $\mathrm{CrO}_{2}$ is metallic. It was proposed that an interatomic exchange interaction may be the source of these discrepancies. If this were the case for $\mathrm{Cr}_{3} \mathrm{O}_{4}$, it is expected that both the $\mathrm{Cr} 3 d$ and $\mathrm{O} 2 p$ emissions should shift to higher binding energy. This is not observed in the UPS spectra; therefore, it is unlikely that such an exchange interaction is significantly influencing the electronic structure.

Another possible explanation for the nature of the $p(2$ $\times 2)$ phase is that it corresponds to a $\gamma-\mathrm{Cr}_{2} \mathrm{O}_{3}(111)$ phase. In analogy to $\gamma-\mathrm{Fe}_{2} \mathrm{O}_{3}$, the $\gamma$ phase of $\mathrm{Cr}_{2} \mathrm{O}_{3}$ is also a cubic spinel structure with random, missing $\mathrm{Cr}$, point defects. Since the $\gamma$ phase has the same stoichiometry as the corundurn structured $\mathrm{Cr}_{2} \mathrm{O}_{3}$, it might also have a similar valence structure. Because the crystal structure is an ill-defined defect structure, calculations of the DOS have not been per- formed to confirm this. Both octahedrally and tetrahedrally coordinated $\mathrm{Cr}$ ions are present in this structure which would give rise to the broadening of the $\mathrm{Cr} 2 p$ core emission which has been observed in previously published XPS data for the $p(2 \times 2)$ phase. ${ }^{9}$ Another factor that should be considered is the experimentally determined lattice constant of $\gamma-\mathrm{Cr}_{2} \mathrm{O}_{3}$ which is $a_{0}=8.36 \AA .^{8}$ If the $p(2 \times 2)$ overlayer maintained the same lattice constant as the bulk $\gamma-\mathrm{Cr}_{2} \mathrm{O}_{3}$ value, a splitting of the $\mathrm{Pt}(111)$ and the $p(2 \times 2)$ LEED spots would be observed since there is a relatively large $6 \%$ lattice mismatch. No splitting was observed which indicates a pseudomorphic growth mode.

The possibility that the $p(2 \times 2)$ phase corresponds to a reconstructed $\mathrm{Cr}_{2} \mathrm{O}_{3}(0001)$ surface has also been considered. If the $\mathrm{Cr}_{2} \mathrm{O}_{3}(0001)$ surface were to reconstruct in a $(\sqrt{3}$ $\times \sqrt{3}) \mathrm{R} 30^{\circ}$ pattern with respect to a bulk-terminated $\mathrm{Cr}_{2} \mathrm{O}_{3}(0001)$ surface, this would result in a $p(2 \times 2)$ LEED pattem with respect to the $\mathrm{Pt}(111)$ substrate. In fact, a previous study of the $\mathrm{Cr}_{2} \mathrm{O}_{3}(0001) / \mathrm{Cr}(110)$ system has revealed that this surface reversibly transforms from a $(1 \times 1)$ symmetry with respect to the $\mathrm{Cr}_{2} \mathrm{O}_{3}(0001)$ surface at room temperature to a $(\sqrt{3} \times \sqrt{3}) \mathrm{R} 30^{\circ}$ overlayer structure at $\sim 150 \mathrm{~K}$ which then converts back to a $(1 \times 1)$ symmetry as the temperature is lowered below $\sim 100 \mathrm{~K} .{ }^{21}$ Since the onset of antiferromagnetic ordering is often accompanied by lattice distortions, they proposed that the transformation from the room temperature $(1 \times 1)$ symmetry to the $(\sqrt{3} \times \sqrt{3})$ R $30^{\circ}$ overlayer structure at lower temperatures might be driven by antiferromagnetic coupling of the surface chromium ions to those in the second layer. It is possible that the magnetic interaction within the initial $p(2 \times 2)$ bilayer of $\mathrm{CrO}_{x}$ on $\mathrm{Pt}(111)$ is significantly different than the interaction for subsequent multilayers which may increase the temperature at which a reconstruction might occur to room temperature. On the other hand, no structural analysis of the $(\sqrt{3} \times \sqrt{3}) \mathrm{R} 30^{\circ}$ $\mathrm{Cr}_{2} \mathrm{O}_{3}(0001) / \mathrm{Cr}(110)$ overlayer has been published at this time. Therefore, it is also possible that the $\mathrm{Cr}_{2} \mathrm{O}_{3}(0001)$ $/ \mathrm{Cr}(110)$ system is undergoing a transformation to the $\gamma-\mathrm{C}_{2} \mathrm{O}_{3}$ phase at low temperatures instead of a simple surface reconstruction. As mentioned above, a broadening of the $\mathrm{Cr} 2 p$ levels is observed with XPS. ${ }^{9}$ For a reconstructed $\mathrm{Cr}_{2} \mathrm{O}_{3}(0001)$, significant broadening is not generally expected since a rearrangement of the surface $\mathrm{Cr}$ ions should not have much of an effect on their local chemical environment.

Another point of interest is the apparent lack of new UPS features which would correspond to the mixing of Pt and $\mathrm{Cr}_{2} \mathrm{O}_{3}$ states for coverages greater than $\sim 0.2 \mathrm{ML}$. This may be explained by considering the growth morphology of the $\mathrm{CrO}_{x}$ film. The previously mentioned STM analysis of this system shows a step flow growth mode with a $2 \mathrm{ML}$ film height. ${ }^{9}$ If there were any changes in the electronic structure and these changes were confined to the interface region, the new features would be buried under the bilayer and may not be easily detected in surface-sensitive UPS spectra. Another consequence of the step flow growth mode is the possibility that the crystal structure of the $\mathrm{CrO}_{x}$ overlayer could be con- 
trolled by changing the substrate misorientation. Since the initial formation of $\mathrm{Cr}_{3} \mathrm{O}_{4}$ may be a direct result of the interaction of the $\mathrm{CrO}_{x}$ with the step edges, it might be possible to grow a uniform $\mathrm{Cr}_{3} \mathrm{O}_{4}$ overlayer through the first two monolayers of growth by using a vicinal substrate.

\section{CONCLUSIONS}

The similarity of the calculated DOS of $\mathrm{Cr}_{3} \mathrm{O}_{4}$ and the measured UPS spectra for low $\mathrm{CrO}_{x}$ coverages indicates that chromium oxide initially crystallizes in a cubic spinel structure. For coverages higher than $\sim 0.2 \mathrm{ML}$, the measured UPS spectra of the $p(2 \times 2)$ phase deviate significantly from the calculated DOS of $\mathrm{Cr}_{3} \mathrm{O}_{4}$. The most probable origin of the $p(2 \times 2)$ phase is a pseudomorphic $\gamma-\mathrm{Cr}_{2} \mathrm{O}_{3}(111)$ overlayer, but it is also possible that the $p(2 \times 2)$ phase results from a reconstructed $\mathrm{Cr}_{2} \mathrm{O}_{3}(0001)$ film. Ultimately, further structural analysis of the $p(2 \times 2)$ phase using a technique such as LEED-IV is required before the crystalline structure can be definitely determined.

\section{ACKNOWLEDGMENTS}

This work has been supported in part by Department of Energy EPSCOR, National Science Foundation EPSCOR, and the Petroleum Research Fund. In addition, P.S.R. would like to acknowledge her support through the Louisiana Board of Regents Support Fund Superior Graduate Student Fellowship Program LEQSF (1996-99)-GH-Z6, and C.A.V. would like to acknowledge support from the UNO College of Science Summer Scholar Program. The NSLS is supported by the Divisions of Materials and Chemical Sciences of the U.S. Department of Energy.
${ }^{1}$ H. C. Galloway, J. J. Benítez, and M. Salmeron, Surf. Sci. 298, 127 (1993).

${ }^{2}$ H. C. Galloway, J. J. Benítez, and M. Salmeron, J. Vac. Sci. Technol. A 12, 2302 (1994).

${ }^{3}$ C. A. Ventrice, Jr., Th. Bertrams, H. Hanremann, A. Brodde, and $H$. Neddermeyer, Phys. Rev. B 49, 5773 (1994).

${ }^{4}$ H. Hannemann, C. A. Ventrice, Jr., T. Bertrams, A. Brodde, and H. Ned-dermayer, Phys. Status Solidi A 146, 289 (1994).

${ }^{5}$ H. Kuhlenbeck and H.-J. Freund, in Growth and Properties of Ultrathin Epitaxial Layers, edited by D. A. King and D. P. Woodruff (Elsevier, New York, 1997), Chap. 9, pp. 340-374.

${ }^{6}$ B. L. Chamberland, CRC Crit. Rev. Solid State Sci. 7, 1 (1977).

${ }^{7} \mathrm{M}$. Hansen and K. Anderko, Constitution of Binary Alloys, 2nd ed. (McGraw-Hill, New York, 1958).

${ }^{8}$ R. W. G. Wyckoff, Crystal Structures, 2nd ed. (Interscience, New York, 1969).

${ }^{9}$ L. Zhang, M. Kuhn, and U. Diebold, Surf. Sci. 375, 1 (1997).

10J. A. Rodriguez, S. Chaturvedi, M. Kuhn, J, van Ek, U. Diebold, P. S. Robbert, H. Geisler, and C. A. Ventrice, Jr., J. Chem. Phys. 107, 9146 (1997).

${ }^{11}$ O. K. Andersen, Phys. Rev. B 12, 3060 (1975).

${ }^{12}$ W. Kohn and L. J. Sham, Phys. Rev, 140, Al133 (1965).

${ }^{13}$ U. von Barth and L. Hedin, J. Phys. C 5, 1629 (1972).

${ }^{14}$ H. van Leuken and R. A. de Groot, Phys. Rev. B 51, 7176 (1995).

${ }^{15}$ K. Schwarz, J. Phys. F 16, L211 (1986).

${ }^{16}$ D. S. McClure, J. Chem. Phys. 38, 2289 (1963).

${ }^{17}$ B. B. Krichevtsov, V. V. Pavlov, R. V. Pisarev, and V. N. Gridnev, Phys. Rev. Lett. 76, 4628 (1996).

${ }^{18}$ C. A. Ventrice, Jr., D. Ehrlich, E. L. Garfunkel, B. Dillmann, D. Heskett, and H.-J. Freund, Phys. Rev. B 46, 12892 (1992).

${ }^{19}$ K. P. Kämper, W. Schmitt, T. Güntherodt, R. J. Gambino, and R. Ruf, Phys. Rev. Lett. 59, 2788 (1987).

${ }^{20}$ D. S. Rodbell, J. M. Lommel, and R. C. DeVries, J. Phys. Soc. Jpn. 21, 2430 (1966).

${ }^{21}$ M. Bender, D. Ehrlich, I. N. Yakovkin, F. Rohr, M. Bäumer, H. Kuhlenbeck, H.-J. Freund, and V. Staemmler, J. Phys.: Condens. Matter 7, 5289 (1995). 